\section{Questión}

Periodismo / Comunicación

ISSN 1669-6581

Apuntes para pensar(nos) en tiempos de Pandemia

Ramiro Coronel Román

Question/Cuestión, Nro.66, Vol.2, agosto 2020

ISSN: 1669-6581

https://perio.un/p.edu.ar/ojs/index.php/question/

IICom - FPyCS - UNLP.

DOI: https//doi.org/10.24215/16696581e474

\title{
Apuntes para pensar(nos) en tiempos de Pandemia
}

\section{Notes to think about pandemic times}

Ramiro Coronel Román

https://orcid.org/0000-0003-4514-3294

ramirocorman@hotmail.com

Licenciado en Comunicación Social (UNLP)

Profesor Adjunto de la Facultad de Periodismo y Comunicación Social, UNLP.

Maestrando de la Facultad de Comunicación de la Universidad de Sevilla.

\section{Resumen}

Pensarnos en presente, en lo cotidiano. Desde la conciencia individual y política. Conocernos propiamente, antes de que intenten seguir expropiándonos. Superar la modernidad conectados a los saberes ancestrales, con la Naturaleza. Este tiempo de Pandemia es nuestra oportunidad y nuestra condición de posibilidad. 


\section{Palabras Clave}

Pandemia, comunicación, modernidad, confinamiento.

\section{Abstract}

Think about us in the present, in the everyday. From individual and political consciousness. Get to know us properly, before they try to further expropriate us. Overcome modernity connected to ancestral knowledge, with Nature. This pandemic time is our opportunity and our condition of possibility.

\section{Key words}

Pandemic, communication, modernity, confinement.

Ver directamente el estado absoluto, la Base de nuestro ser, es la Visión; el medio para estabilizar esta Visión y convertirla en una experiencia ininterrumpida es la Meditación, e integrar la Visión en nuestra vida y nuestra realidad entera es lo que se entiende por Acción.

Sogyal Rimponché, El libro Tibetano de la vida y de la muerte

Mercedes, Buenos Aires, un mes y dos días de confinamiento.

Empecé el confinamiento 6 días antes de la declaración por parte del Gobierno Nacional. Movilizado por los casos en España, el pedido de atención del Presidente Alberto Fernández, me caló profundo en aquellos días tempranos cuando parecía todavía que acá no iba a pasar nada. Desde ese momento, he 
leído y consumido mucho de lo que circula. Desde teorías del fin del capitalismo, hasta las conspiraciones creíbles pero poco demostrables. Debo confesar, que estas últimas, son mis preferidas. En el medio, los medios. Lo que hace años denunciamos como manejo de la agenda con todas sus trampas, en estos tiempos, todo tiene otro cariz. Es alarmante ver el uso y abuso que hacen de la información, que si bien no nos sorprende, nos obliga a denunciar que esa no es la comunicación que queremos. Que esa no es la prensa que se merece la sociedad, que nos merecemos como pueblo.

Sinceramente, nada me convence. Creo que no son momentos de sacar a relucir marcos teóricos, propuestas metodológicas ni apuestas políticas. No digo no pensar y reflexionar sobre qué es lo que nos ha traído hasta aquí, pero sin dudas, considero que la futurología hay que dejarla para otro momento. El mundo no puede pensarse desde opuestos tales como Zizek o Byung-Chul Han. Ambos autores quemaron sus plumas para salir a contarnos mundos que posiblemente lleguen. Como siempre las miradas posmodernas eurocéntricas, se apuran para narrarnos y contarnos cómo es, cómo fue y cómo va a ser el mundo.

Pero ¿qué queda de América Latina metida en todo este berenjenal? Sin dudas, mirar nuestro continente hace una vez más, más rica la historia. Cómo se han ido llevando adelante las políticas públicas en cada uno de los Estados latinoamericanos, nos sirve para visualizar y entendernos en este contexto. Entendernos en este contexto es crucial para ir construyendo un futuro que nos habilite nuevas posibilidades.

Pero cómo pensar en un futuro sin pensar en los cientos de cuerpos muertos en las calles de Guayaquil. Cómo pensar un futuro posible con Brasil en manos de un sociópata que echa a un Ministro de Salud que quiere respetar las 
medidas que mundialmente se están proponiendo como única respuesta a enfrentar al Covid-19 y que a contracorriente del distanciamiento social, asume un flamante ministro a los besos y abrazos en un acto público. Cómo pensar en un futuro posible cuando desde Chile, contabilizan a los muertos como recuperados porque no transmiten la enfermedad. Cómo pensar el futuro cuando en el Norte, los pro Trump hablan de "su cuerpo, su decisión" a la hora de no usar barbijos y en contra de las medidas de aislamiento obligatorio. Cómo pensar en el futuro cuando vemos que en la dictadura boliviana hace uso y abuso de su poder y toma medidas como el encapsulamiento de una región, lo que constituye un delito de lesa humanidad (Rodríguez, 2020).

Pero también, nos interpela a pensar el futuro, un ejemplo en la región, que es el de la República Argentina. Pocas veces en la historia, un Gobierno Nacional ha actuado con tanta determinación en favor de las grandes mayorías. Mientras veíamos como en Europa el coronavirus llegaba sin poder ponerle un freno, en Argentina se fueron tomando decisiones drásticas para ponerle freno a la curva de contagios. Todavía es pronto para sacar conclusiones sobre si ha podido vencer esta peste del siglo XXI, pero los números indican que se han hecho las cosas bien. Se ha priorizado la salud por encima de la economía y eso nos va a traer menos disgustos.

Mas esto no quiere decir que se esté condenando a un pueblo trabajador. Se articulan programas de ayuda, subsidios, préstamos. Se ha puesto en marcha toda la red del Estado para intentar llegar a todos los sectores. Desde el Gobierno Nacional han reiterado varias veces que esa dicotomía no existe, que cuidar la salud es cuidar la economía. Pero los que tenemos memoria de lo que son los gobiernos neoliberales, sabemos que si se prioriza la economía, los 
muertos se contarían de a cientos o de a miles, como está pasando en los estados gobernados por las economías neoliberales.

Esta experiencia nuestra, nos habilita también otras líneas para pensar en el futuro. No desde las concepciones prefiguradas, sino desde nuestra propia historia. Cuando todo parece sumamente oscuro y ruín, aparecen políticas públicas que ponen la atención en el pueblo. Parece todo muy romántico, pero es la sensación de cuidado por parte de un gobierno. Algo que debería ser común, aparece como una excepción que es reconocida incluso por aquellos que están en oposición absoluta con la ideología de quienes conducen hoy el Estado.

Como afirmaba más arriba, no siento que sea momento de hacer futurología o apostar alguna de las hipótesis que nos plantean aquelles que supuestamente piensan. Pero el presente, lo que tenemos ahora es tan abrumador que nos permite pensar muchas dimensiones individuales y colectivas. Nadie se salva solo, pero sin la suma de nuestras soledades y nuestras atenciones propias no nos salvamos a nosotros mismos ni a la comunidad. El repensar esta sociedad, no solo en sus condiciones materiales de existencia, sino en sus relatos que habilitan modos de ser y estar en el mundo. De un día para otro, los doctorados, los máster y los trabajos de oficina pasan a ser de menos importancia que aquellos que han sido considerados de segunda categoría durante décadas: que bofetón de realidad para muches que miraban por encima del hombro a cajeres de supermercado, a recolectores de basura, al personal de salud.

Es momento de meditar, de mirarnos, de entendernos. Capaz que es momento hasta de rever nuestras creencias, de encontrarnos pensando otros mundos posibles. Desde nuestro lugar inmediato que es nosotros mismos. Considero 
que es momento de romper con ideologías, con dogmas, con las estructuras que hasta hoy nos han servido para pensar el mundo, pero que ya no sirven más. Y esto no lo pienso desde un lugar new age y posmoderno, ni renegando de la política, lo pienso como una oportunidad que tenemos de dar cuenta de que el mundo normal que teníamos no sirve, no sólo en nuestro país sino en el mundo entero. Que como es adentro es afuera, que como afirma Yuval Noah Harari: "ya que es imposible desglobalizar la ecología y el progreso de la ciencia, y ya que el coste de desglobalizar la economía seguramente sería prohibitivo, la única solución real es globalizar la política. Esto no significa establecer un <<gobierno global >>, una visión dudosa e irrealista, sino más bien que las dinámicas políticas internas de los países e incluso de las ciudades den mucha más relevancia a los problemas e intereses globales (Harari, pág. 148).

Por más buena voluntad que se tenga, este mundo necesita de la elevación de nuestra consciencia para tomar decisiones. Si cuando todo esto pase, volvemos a construir un mundo para pocos, un mundo que extingue sus selvas en favor del monocultivo, un mundo que permite que el alimento sea envenenado con agrotóxicos, un mundo donde exista el neoextractivismo, un mundo donde el $1 \%$ de la población tiene más recursos que el 99\% restante, nada de todo esto habrá servido ni tampoco habrá valido la pena.

Hay que prestarle atención al cuerpo. Porque esta crisis que azota al mundo, por primera vez en mucho tiempo, no viene dada por factores de especulación financiera. Esta vez, la crisis viene porque el cuerpo se enferma. El virus enferma los cuerpos, siguiendo el pensamiento de Franco Berardi: "Cuando hablo de cuerpo me refiero a la función biológica en su conjunto, me refiero al cuerpo físico que se enferma, aunque de una manera bastante leve, pero 
también y sobre todo me refiero a la mente, que por razones que no tienen nada que ver con el razonamiento, con la crítica, con la voluntad, con la decisión política, ha entrado en una fase de pasivización profunda. Cansada de procesar señales demasiado complejas, deprimida después de la excesiva sobreexcitación, humillada por la impotencia de sus decisiones frente a la omnipotencia del autómata tecnofinanciero, la mente ha disminuido la tensión. No es que la mente haya decidido algo: es la caída repentina de la tensión que decide por todos. Psicodeflación."

Pasar a la acción en el sentido tibetano del término. Pensar en nuestra existencia se convierte en un menester. El vacío y la soledad que se siente en este momento donde el ruido y el plástico del capitalismo voraz ha quedado unos días, semanas, meses en silencio. "Es probable que las personas separadas de su cuerpo, sentidos y ambiente físico se sientan alienadas y desorientadas. Los expertos suelen atribuir estos sentidos de alienación a la reducción de los vínculos religiosos y nacionales, pero perder el contacto con el propio cuerpo probablemente sea más importante. Los humanos han vivido millones de años sin religiones ni naciones; es probable que también puedan vivir felices sin ellas en el siglo XXI. Pero no pueden vivir felices si están desconectados de su cuerpo. Si uno no se siente cómodo en su cuerpo, nunca se sentirá cómodo en el mundo." (Harari pág, 112).

Es el momento de pensarnos en el presente, en nuestro actos cotidianos. En nuestro nivel de consciencia, no solo política. Consciencia individual. Conocernos a nosotros mismos antes de que las grandes corporaciones nos conozcan. Animarnos a pensar espiritualmente el materialismo histórico. Romper con las estructuras modernas y posmodernas para construir una humanidad más humana. Un mundo habitable en conexión con la naturaleza, 
en conexión con los saberes ancestrales, previos a la modernidad. Un mundo con otras lógicas. Es momento de ver por qué estamos como estamos y qué hemos hecho nosotros para que esto esté así. El futuro es incierto, pero el presente está aquí y nos obliga a la reflexión y a la acción de nuestro cuidado. Para salvarnos a nosotros y salvar al mundo entero.

\section{Bibliografía}

- Agencias, R. (2020). Chile contabiliza a los muertos como recuperados "porque ya no pueden contagiar". www.lavanguardia.com. Retrieved 13 April 2020, from https://www.lavanguardia.com/internacional/20200413/48469884428/chil e-contabiliza-muertos-recuperados-no-contagiar-coronavirus.html.

- Byung-Chul Han. (2020). La emergencia viral y el mundo de mañana Byung-Chul Han (22 de marzo). Sopa De Wuhan, (1), 97-112. Retrieved 27 April 2020, from.

- Gilbert, A. (2020). Muertos en las calles: la imagen que resume la crisis del coronavirus en Ecuador. www.elperiodico.com. Retrieved 2 April 2020 , from

https://www.elperiodico.com/es/internacional/20200402/muertos-en-lascalles-la-imagen-que-resume-la-crisis-sanitaria-en-ecuador-7914370.

- Harari, Y. (2018). 21 lecciones para el siglo xxi/ 21 lessons for the 21st century (1st ed., pp. 112; 148). DEBATE.

- Nepomuceno, E. (2020). En plena pandemia Bolsonaro cambia ministro / Mientras los números se disparan el presidente echa a todo el equipo de Salud. PAGINA12. Retrieved 16 April 2020, from 
https://www.pagina12.com.ar/259974-en-plena-pandemia-bolsonarocambia-ministro.

- Rimponché, S. (2015). El libro tibetano de la vida y de la muerte (1st ed., p. 206). Ediciones Urano.

- Rodríguez, A. (2020). Denunciamos ante la comunidad internacional la violación de los derechos humanos en la región del trópico de Cochabamba.. Lecture, Cochabamba. Bolivia.

- Sandoval, P. (2020). La protesta contra el confinamiento crece en Estados Unidos alentada por Donald Trump. EL PAís. Retrieved 19 April 2020, from https://elpais.com/internacional/2020-04-19/la-protestacontra-el-confinamiento-crece-en-estados-unidos-alentada-por-donaldtrump.html.

- Zizek, S. (2020). Coronavirus es un golpe al capitalismo al estilo de 'Kill Bill' y podría conducir a la reinvención del comunismo. Sopa De Wuhan, (1), 21 - 28. Retrieved 27 April 2020, from. 